\title{
A textura musical na delineação formal de Dérives 1 de Pierre Boulez
}

JORGE LUIZ DE LIMA SANTOS

Universidade Estadual de Campinas (jorgelsantos 02@gmail.com)

\section{Introdução}

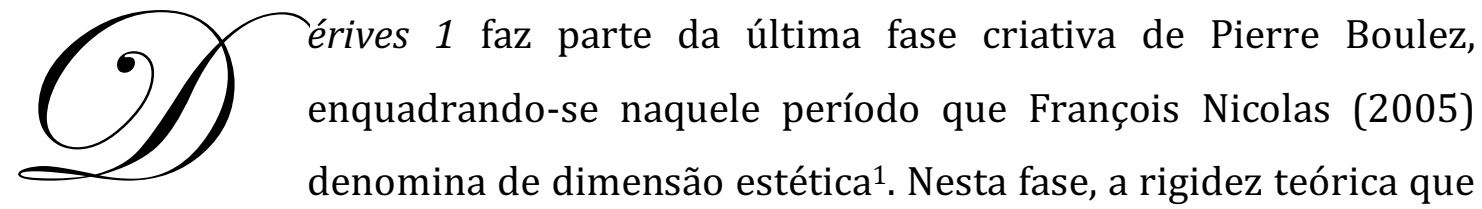

marcou a maior parte das obras de Boulez por mais de 30 anos dá lugar a uma tentativa de valorizar o aspecto aural.

Escrita para um pequeno conjunto de câmara (flauta, clarineta, violino, violoncelo, vibrafone e piano), a peça é a primeira de três composições cujo material deriva, como o nome indica, de outra obra, Repóns (1980/82). De certa forma, a peça inclui a noção de work in progress, surgida na produção de Boulez em períodos anteriores, na qual o compositor continuamente revisita algumas obras e as reelabora. Outra característica que apresenta é a contraposição de instrumentos percussivos com os de sons contínuos, como acontece em Le Marteau sans Maître. Dérive 1 foi estreada em 1985 pela London Sinfonietta, em homenagem a Sir William Glock.

Nesse trabalho, buscamos demonstrar como a textura se apresenta como elemento central no delineamento da forma (entendida como elemento de unidade e coesão entre partes e todo) e no sentido e direção da obra como um todo. Antes de tratar da textura, iremos abordar rapidamente, de forma descritiva, o seccionamento formal (ou seja, a divisão temporal apenas) e a harmonia de maneira a permitir uma visão geral da obra.

\section{Forma}

Dérives 1 está claramente dividida em três seções, como mostra o quadro 1:

\footnotetext{
${ }^{1}$ Ver SANTOS, 2014, p. 79.
} 


\begin{tabular}{|c|c|c|}
\hline A & B & Coda \\
\hline c. $1-27$ & c. $27-46$ & c. $47-55$ \\
\hline
\end{tabular}

Quadro 1: Divisão formal de Dérives 1 de Pierre Boulez.

A seção A (c. 1-27) é caracterizada por "um pulso constante e lento, articulado por aparições de vertiginosas notas rápidas de caráter ornamental” 2 (MOGUILLAKY, 2004, p. 2). As notas longas e estáticas são contrapostas a uma grande profusão de apojaturas que desenvolvem uma textura crescente em densidade-número, a cada momento mais complexa. A seção B (c. 27-46) é marcada por uma mudança abrupta de densidade-número e de agógica (Très lent). A Coda (c. 47-55) funciona como uma reminiscência da primeira seção, trazendo a ideia de tema que se repete, porém de maneira muito mais efêmera e com caráter conclusivo. A simples observação da textura, ainda que superficial e distanciada, sugere sua importância na organização formal da peça.

\section{Alturas/Harmonia}

A estrutura de alturas de Dérives 1 (a mesma para Répons e Dérives 2) é construída a partir de seis classes de altura que correspondem ao nome "Sacher"3 (Paul Sacher) ${ }^{4}$ (Exemplo 1):

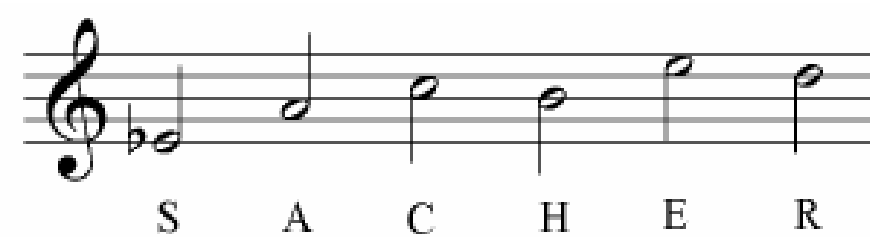

Exemplo 1: Classes de altura em Dérives 1 de Pierre Boulez (MOGUILLANSKY, 2004, p. 45).

\footnotetext{
2 "Un pulso constante lento (la negra igual a 40) articulado por repentinas apariciones de vertiginosas notas rápidas de carácter ornamental" (Moguillaky, 2004, p. 2).

${ }^{3}$ Como se observa no Figura 1, Boulez utiliza duas notações diferentes para estabelecer uma relação com o nome Sacher. As cinco primeiras letras se referem a notação alemã e a última, "r", a inicial da nota ré.

${ }^{4}$ Paul Sacher (1906-1999) foi um regente, patrono e executivo suíço. Ele criou e dirigiu a Basler Kammerorchester, dedicada à música moderna, co-fundou a Schola Cantorum Basiliensis em Basel (Suíça), encomendou e financiou obras de nomes seminais na música do século XX como Divertimento for Strings e Music for Strings, Percussion and Celesta de Bartók, Die Harmonie der Welt de Hindemith, Metamorphosen Richard Strauss e A Sermon, a Narrative, and a Prayer de Stravinsky, além de obras de Boulez, Britten, Berio, Ginastera, Henze, Lutoslawski entre outros (ver: http://www.paul-sacherstiftung.ch/en/about_the_foundation/paul_sacher.html).
} 
É curioso observar que nessa fase Boulez não mais necessita de uma série de doze sons para elaborar seu material melódico-harmônico, além da mesma ser apresentada verticalmente, formando um bloco.

Como em Le Marteau ${ }^{5}$, a verticalização da sequência de alturas do Figura 1 resulta em um complexo de sons ou bloco sonoro ${ }^{6}$ (Exemplo 2):

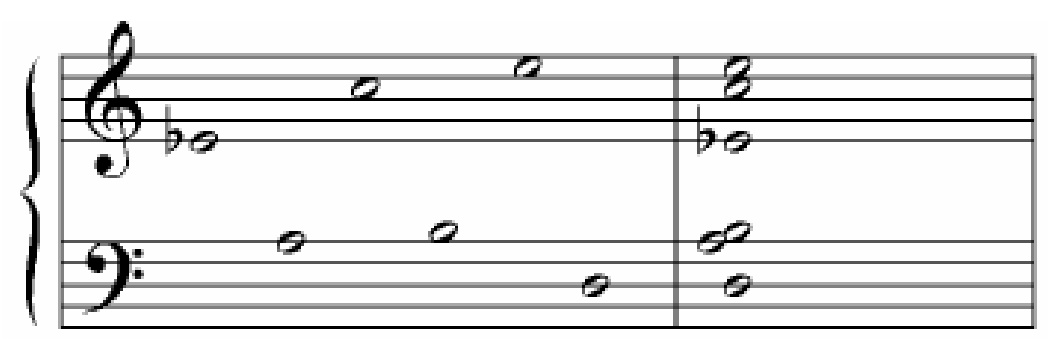

Exemplo 2: Bloco sonoro original em Dérives 1.

Toda a estrutura de alturas da música está construída com base no acorde ${ }^{7}$ apresentado (Figura 2) e em suas cinco permutações. Boulez obtém os outros blocos sonoros a partir operações de rotação e transposição, de modo que a primeira altura de cada bloco sempre seja mi bemol, que funciona como uma espécie de pivô (Exemplo 3):

\footnotetext{
${ }^{5}$ Ver SANTOS (2014, p. 87).

${ }^{6}$ Ibid.

${ }^{7}$ Moguillansky utiliza a palavra "acorde" para designar a verticalização dos sons em grupos. Utilizamos aqui, além deste, o termo bloco sonoro, que particularmente consideramos mais adequado, tendo em conta a própria preferência de Boulez. Assim, nesse contexto, acorde, bloco sonoro e complexo de sons serão utilizados com o mesmo sentido.
} 
A
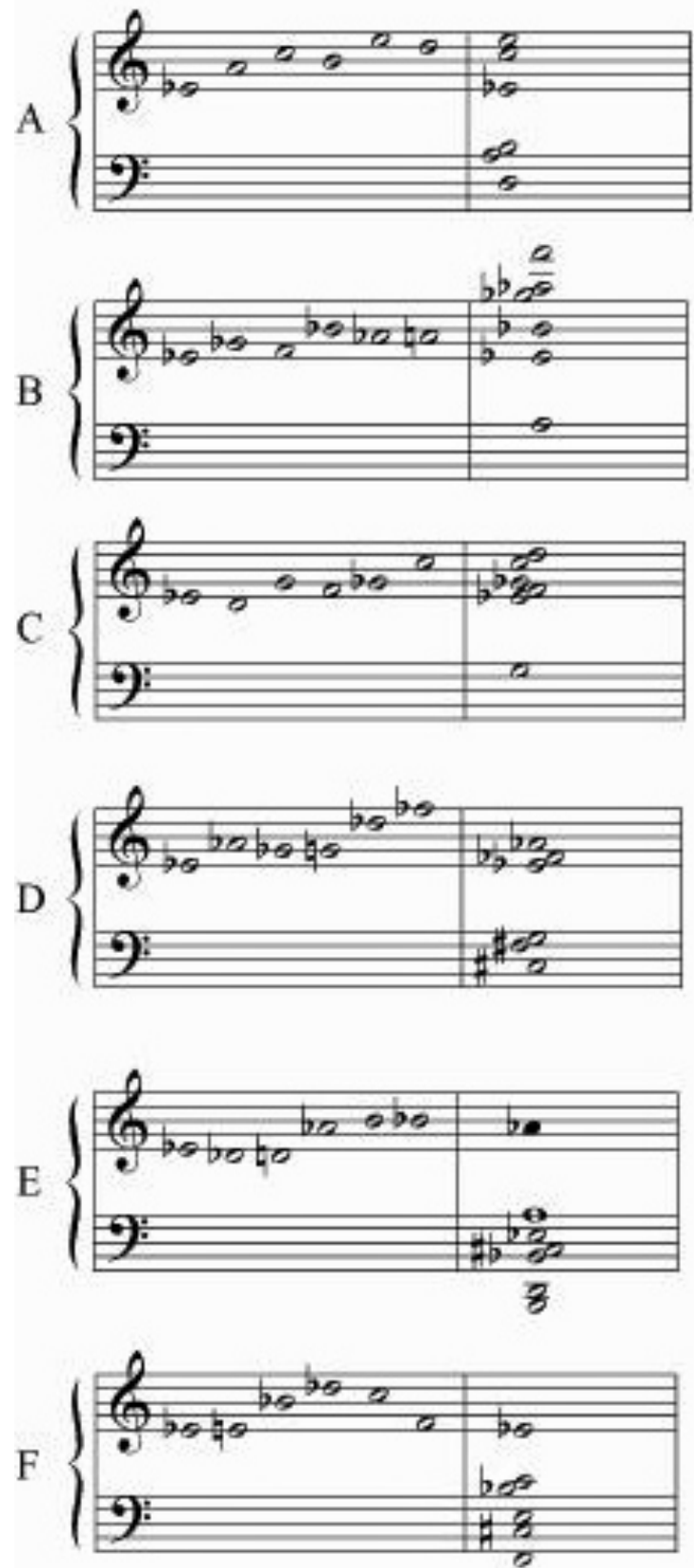

Exemplo 3: Seis blocos sonoros de Dérives 1 de Pierre Boulez.

Os seis acordes contêm o total cromático e apresentam entre si algumas alturas comuns que funcionam como pivôs para as transposições. Como derivam de uma única estrutura de alturas, possuem as mesmas relações intervalares internas. Esse procedimento lembra a técnica de multiplicação de frequências utilizada por Boulez também em Le Marteau para gerar os domínios harmônicos que formam a harmonia da obra. ${ }^{8}$ Aqui, porém, o compositor o faz de maneira mais simples e direta. Moguillansky aponta para outra característica presente na harmonia da obra, 
que denomina de "registração fixa de altura" que tornaria mais audível a construção acima mencionada:

\begin{abstract}
Este procedimento, que aparece com frequência na música de Boulez desde a sua Segunda Sonata para piano (1947-8), caracteriza-se por fixar algumas ou todas as notas de uma escala cromática em um registro específico de maneira que cada vez que aparece uma determinada nota, ela acontece na mesma oitava. Aqui [em Dérives 1] cada acorde é sempre usado na transposição da mesma oitava e na mesma inversão9 ${ }^{9}$ (MOGUILLANSKY, 2004, p. 45).
\end{abstract}

Na sua análise das alturas, Moguillansky propõe a existência de um "acorde 0 " que conteria todas as alturas utilizadas nos seis blocos, somadas a algumas "notas estranhas" que aparecem como apojaturas em momentos pontuais. Tal acorde funcionaria como uma abstração a se descobrir, como se cada um dos seis acordes revelasse só uma de suas partes. 0 Exemplo 4 apresenta o "acorde 0" (as notas brancas) ao lado das "notas estranhas" (pretas), ausentes dos seis blocos sonoros, embora façam parte da peça:

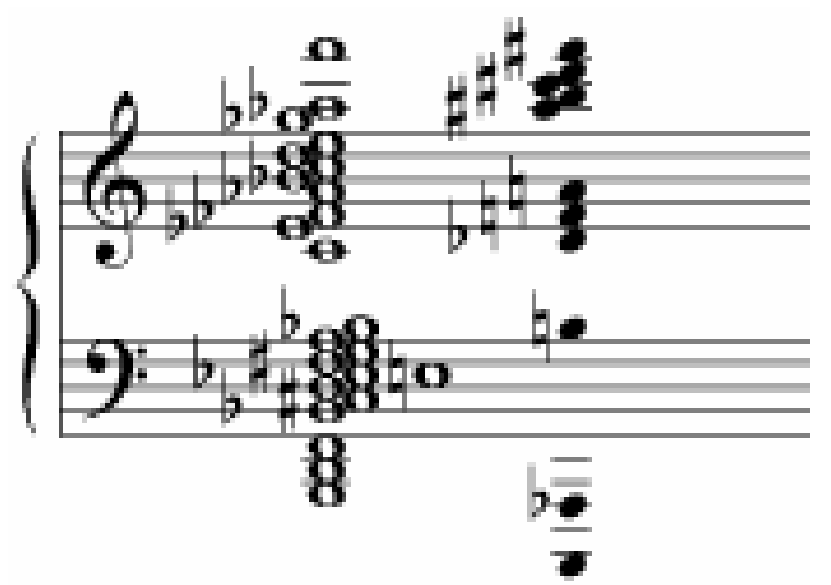

Exemplo 4: "Acorde 0" e "notas estranhas" em Dérives 1 de Pierre Boulez (MOGUILLANSKY, 2004, p. 46).

\footnotetext{
9 “Este procedimiento, que aparece con frecuencia en la música de Boulez desde su Segunda sonata para piano (1947-8), se caracteriza por fijar algunas o todas las notas de la escala cromática en un registro específico de manera que cada vez que aparece una nota lo hace en la misma octava. Aquí cada acorde está siempre usado en la transposición de la misma octava y en la misma inversión" (MOGUILLANSKY, 2004, p. 45).
} 
Toda a harmonia da obra é construída a partir do encadeamento desses blocos ou acordes. As relações intervalares, como destaca Deliège (2003, p. 724), exercem uma forte pressão diatônica para uma estruturação harmônica cromática. Se observarmos os seis hexacordes, veremos claramente a relação diatônica (Quadro 2) presente internamente em cada um deles:

Mi b Lá Dó Si Mi Ré

$\underline{\mathrm{Mi}}, \mathrm{Sol}_{2} \mathrm{Fá} \mathrm{Si}_{2} \mathrm{La}$, La

Mi, Ré Sol Fá Sol, Dó

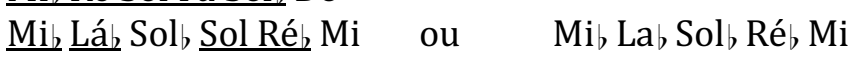

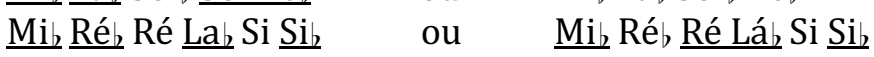

$\underline{M i}$, Mi Si $\underline{\text { Séb }}$ Do Fá

Quadro 2: Relações diatônicas nos seis hexacordes de Dérives 1 de Pierre Boulez (adaptado de DELIÈGE, 2003, p. 724).

Para além da mera constatação, essas relações internas têm impacto direto no resultado geral da harmonia, que tende a evocar a centralidade tonal, corroborando uma tendência verificada nessa fase criativa de Boulez pela preocupação com o aspecto aural da obra.

Moguillansky fez um mapeamento da utilização dos blocos em toda a peça. No Exemplo 5, as notas brancas representam as alturas que são sustentadas e as pretas as alturas que compõem as apojaturas ou notas de adorno. Interessa-nos nessa análise harmônica, especialmente, observar como os blocos sonoros dialogam com outros parâmetros, notadamente, a textura, na delineação da forma e na dinâmica do discurso musical. 

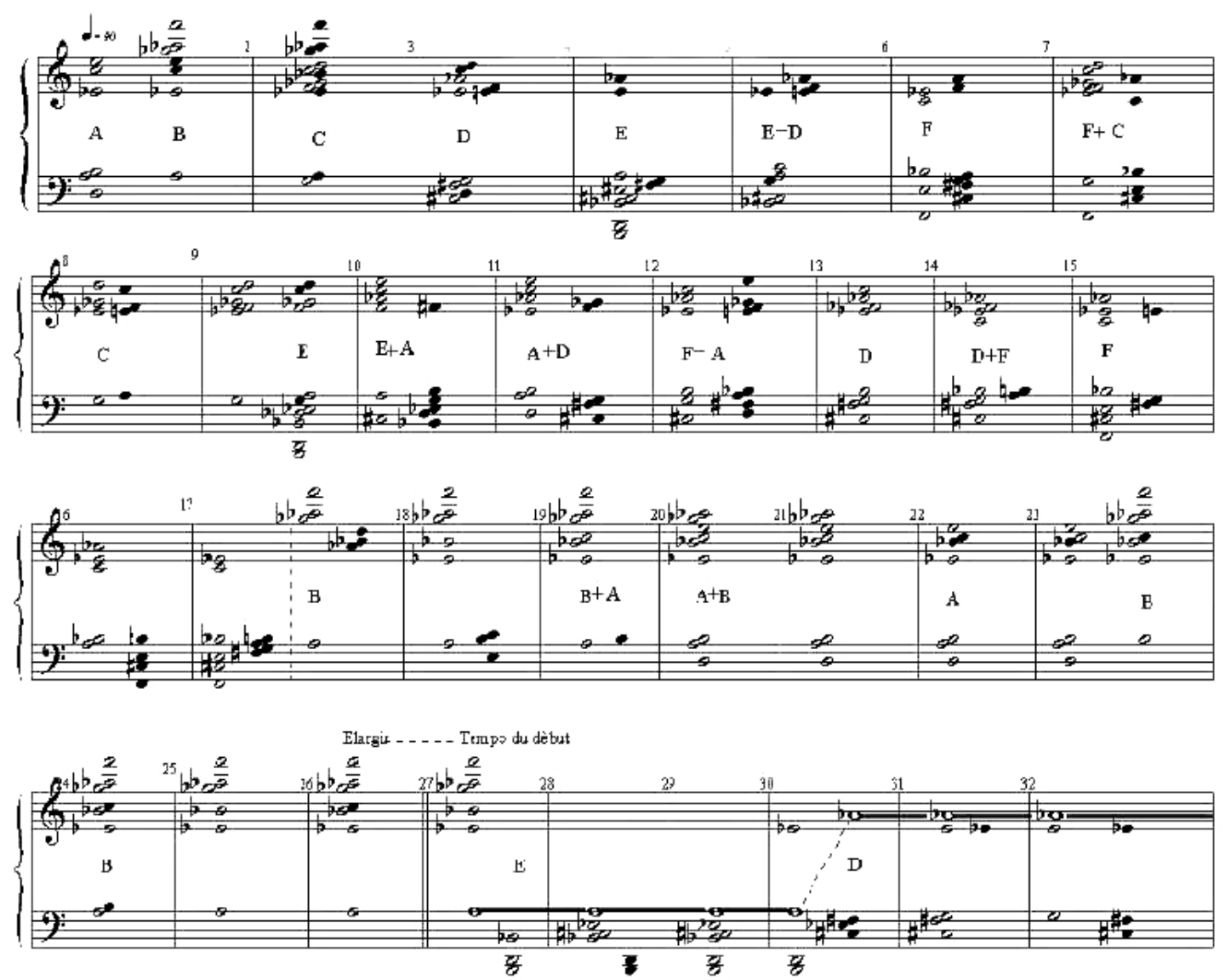

108
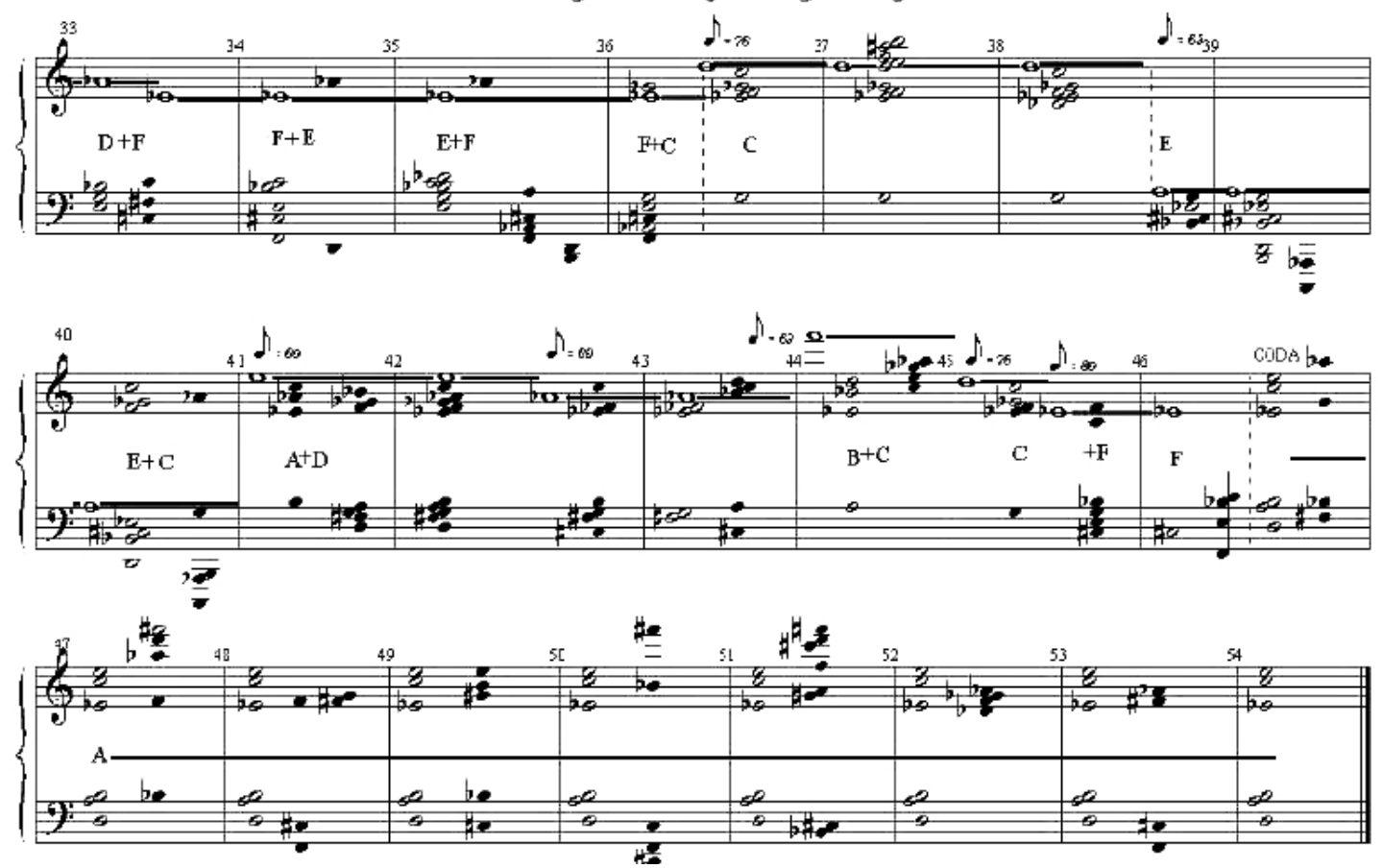

Exemplo 5: Estrutura harmônica de Dérives 1 de Pierre Boulez (MOGUILLANSKY, 2004, p. 47). 


\section{Metodologia: teoria textural de Wallace Berry e Análise Particional (AP)}

A abordagem que fundamentará a análise textural e suas correlações com a harmonia e a forma tem como enfoque o mapeamento quantitativo do fenômeno textural. A textura é, então, aqui entendida essencialmente como as relações verticais entre as partes sonoras, ou seja, as relações de congruência e/ou não congruência (BERRY, 1987, p. 184). Estes são dois conceitos fundamentais da visão de Wallace Berry sobre a textura. Sua teoria, todavia, não discute a fundo o problema da janela de observação, ou seja, se, para determinar essas relações de congruência ou não, deve-se considerar um compasso, um tempo, um ataque, uma seção, etc. É partir dessa lacuna que Análise Particional (2004), desenvolvida por Pauxy GentilNunes, entra como ferramenta principal de nossa análise. Primeiro ao definir esta janela de observação como sendo o ataque, segundo por desenvolver um software, PARSEMAT, que tendo essa janela como princípio, mapeia todos os ataques e suas relações binárias entre si, resultando num mapeamento exaustivo de todas as relações de congruência ou não congruência entre as partes sonoras ao longo da obra, ou do trecho, expostas num gráfico espelhado que confronta os movimentos destes dois tipos de relação, chamados, como veremos a seguir, de dispersão e aglomeração. É preciso frisar, entretanto, que não se trata de uma análise puramente quantitativa. A Análise Particional propõe categorias qualitativas que serão utilizadas aqui de forma a nos permitir a extração de informações relevantes para o papel estrutural, no nosso entender, que a textura exerce na obra.

A Análise Particional (doravante, AP) é parte de um projeto de pesquisa de maior amplitude, formulado em 2003, desenvolvido por Pauxy Gentil-Nunes. 0 principal foco da pesquisa é a observação dos aspectos da textura ligados às relações musicais de simultaneidade, e lidos a partir de conceitos da Teoria das Partições de Inteiros (ANDREWS, 1984). Seu desenvolvimento se deu a partir da teoria textural de Wallace Berry (1987), mas depois se ampliou como corpo teórico, permitindo a construção de uma rede de conceitos abstratos que podem ser aplicados a diversos parâmetros (relações rítmicas entre partes instrumentais ou vocais concorrentes; relações lineares internas a uma estrutura melódica; timbre, espacialização, entre outros). Entre as principais aquisições da teoria, está a construção de uma taxonomia exaustiva (lista de todos os estados possíveis de combinações texturais a 
um determinado grupo instrumental), e a possibilidade de homologia entre campos diversos da textura (por exemplo, o estabelecimento de uma relação biunívoca entre textura e melodia, ou de timbre orquestral e configurações espaciais, mantendo a estrutura retórica básica).

A partição é a representação de um número inteiro pela soma de partes

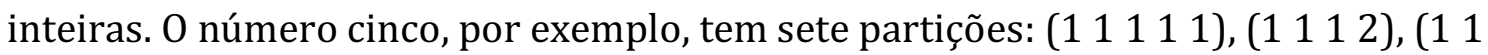
3), (1 2 2), (1 4), (2 3), (5) (GENTIL-NUNES, 2009, p. 6). A função $p$ (n), apesar de sua aparente singeleza, é extremamente complexa e ocupa matemáticos por séculos. Na combinação de partes instrumentais, ocorre o particionamento musical, ou seja, a distribuição ou agrupamento de elementos individuais em blocos funcionais.

A AP investiga a formação das partições a partir das relações entre seus elementos individuais (observados sob o ponto de vista pragmático). Essas relações podem ser de concordância, identidade ou convergência, por um lado, e discordância, contraste ou divergência, por outro. A partir desta distinção, tendemos a agrupar e separar os elementos, formando então as partes. Nesse processo, a contagem dos dois tipos de relação traz uma importante informação sobre as partições - seu grau de massa ou peso (aglomeração) e seu grau de diversidade ou variedade (dispersão). Os índices resultantes desse processo são a base para a AP, formando o par ordenado aglomeração-dispersão $(a, d)$, que é a base para os cálculos e produção de gráficos (GENTIL-NUNES, 2009, p. 36).

Cada partição apresenta um par ordenado, sendo que algumas partições compartilham seus pares. A estrutura fractal e caótica resultante da plotagem dos índices $(a, d)$ como coordenadas em um gráfico cartesiano gera o particiograma estrutura que é ao mesmo tempo um espaço de fase (uma vez que resume visualmente todo o comportamento dinâmico de um determinado sistema, que pode ser, no caso, um quarteto de cordas, um instrumento, ou no caso específico deste trabalho, o campo criativo do compositor), e a representação da taxonomia exaustiva das configurações texturais e sua topologia (ou seja, reflete também o grau de proximidade ou parentesco entre as partições e outras relações funcionais).

O particiograma também corresponde a uma estrutura da teoria das partições chamada de Reticulado de Young, sendo que a versão deste reticulado, com as informações próprias da AP, é chamada de RYP (Reticulado de Young Particional). 
Cada situação musical oferece possibilidades de configuração com limites claros - e por isto, o conjunto de particionamentos possíveis constitui o que na AP é chamado de conjunto-léxico. Ele é basicamente a lista de todas as partições de 1 até $\boldsymbol{n}$, considerando $\boldsymbol{n}$ como o limite dentro do aspecto observado. Por exemplo, um quarteto de cordas pode ser combinado instrumentalmente de 11 maneiras diferentes, cada uma correspondendo a uma partição. Esse número (11) é chamado na AP de soma-léxico do número quatro.

A enumeração das partições de um determinado número, seu conjunto-léxico e sua soma-léxico são fornecidas pelo programa Partitions, que é disponibilizado online.

Gentil-Nunes propôs como principio de investigação três aplicações básicas da $\mathrm{AP}$, ligadas à textura (particionamento rítmico), melodia (particionamento linear) e forma (particionamento de eventos).

O particionamento de eventos observa a concorrência entre ideias definidas pelo compositor, seguindo o exemplo de Cage em Music of Changes, ou seja, a relação entre camadas significantes para o trabalho de produção. A superposição de materiais semelhantes (de acordo com o critério do compositor) gera aglomeração, enquanto a concorrência entre materiais contrastantes gera a dispersão. Ou seja, a aglomeração é lida como homogeneidade de conteúdo, enquanto a dispersão significa a maior quantidade de material diverso apresentado simultaneamente.

Este jogo de combinações entre ideias semelhantes e contrastantes tem impacto direto na forma, entendida tanto no sentido tradicional (segmentação, equilíbrio) quanto no sentido da materialidade do resultado sonoro.

\section{Análise Textural e Forma}

No indexograma geral de Dérives 1 (Figura 1) é possível observar algumas características globais do tratamento dado às partes sonoras. 0 índice $a$ (aglomeração) se mantém praticamente nulo, com poucos movimentos de afastamento do zero. 0 índice de dispersão $d$, por outro lado, é marcado por constantes movimentos oblíquos convergentes e divergentes. Em todo o indexograma - a despeito de algumas diferenças momentâneas que mencionaremos 
a seguir - observa-se a predominância do movimento de revariância $(-r, r){ }^{10}$, caracterizado por alternâncias do índice $d$ enquanto o índice $a$ se mantém fixo. Evidentemente, em detalhes, percebe-se que o índice $a$ não está totalmente fixo. Como é possível verificar na Figura 2 - entre os pontos de tempo 0 e 25 - sua movimentação é bastante discreta, representando quase uma linha reta com brevíssimos afastamentos do zero e duas microbolhas:

112

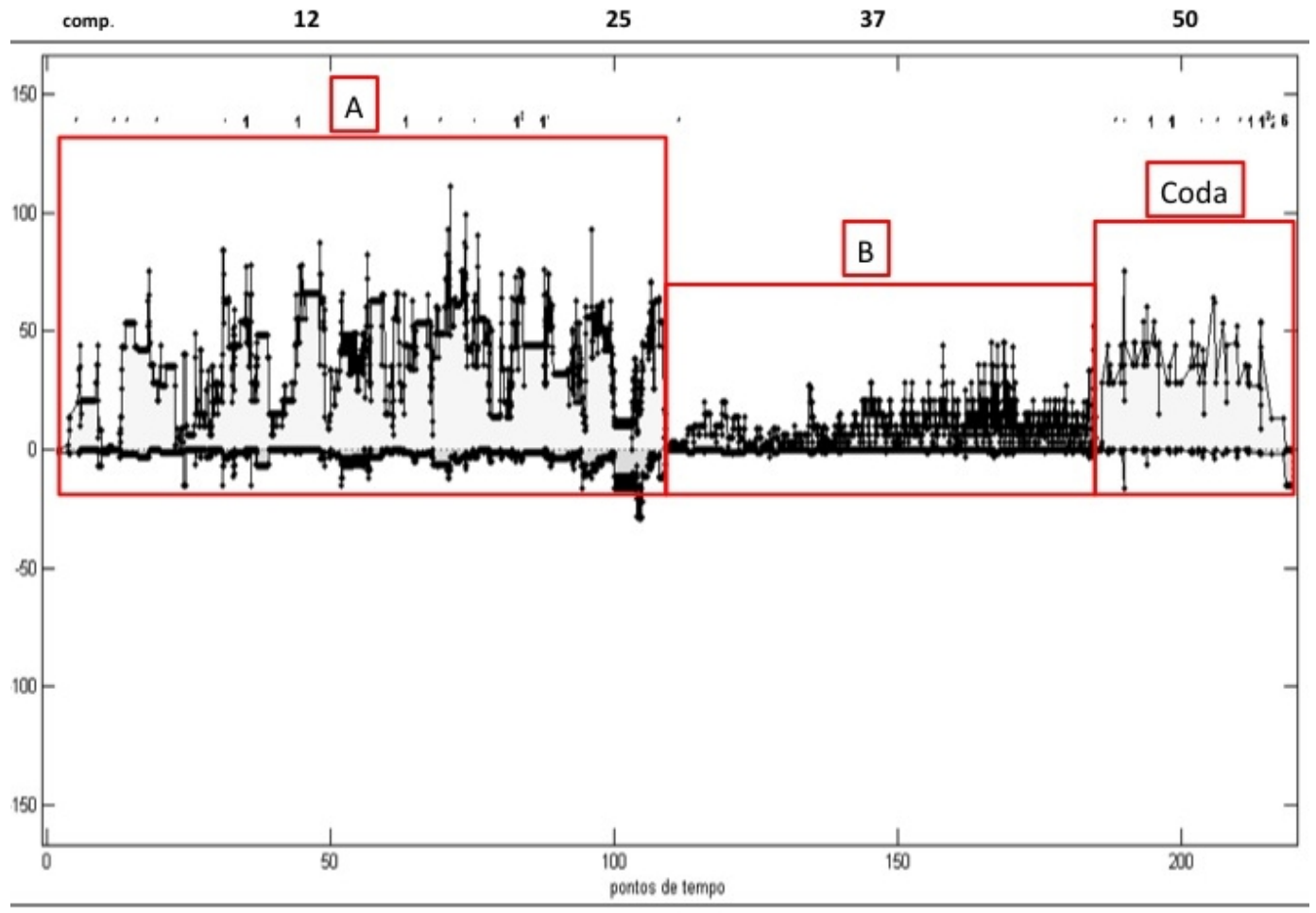

Figura 1: Indexograma geral de Dérive 1 de Pierre Boulez. Gráfico gerado pelo programa Parsemat (GENTIL-NUNES, 2004).

Na Figura 2, podemos observar uma diferença marcante na amplitude dos movimentos oblíquos do índice $d$ que, não por acaso, coincidem com o delineamento da forma geral da música. Verifica-se, na seção A, a presença de picos com o surgimento de um grande número de bolhas. De maneira contrastante, em B, tal ação incessante arrefece, trazendo inicialmente o índice $d$ próximo a zero. Embora ainda prevaleça o movimento de revariância, os picos passam a ter amplitudes significativamente menores, gerando um menor número de bolhas de tamanhos bem mais discretos. Na Coda, o índice $d$ volta a apresentar picos e bolhas, porém com 
amplitudes e duração menores, retomando à configuração textural da seção A, ainda que de maneira mais limitada.

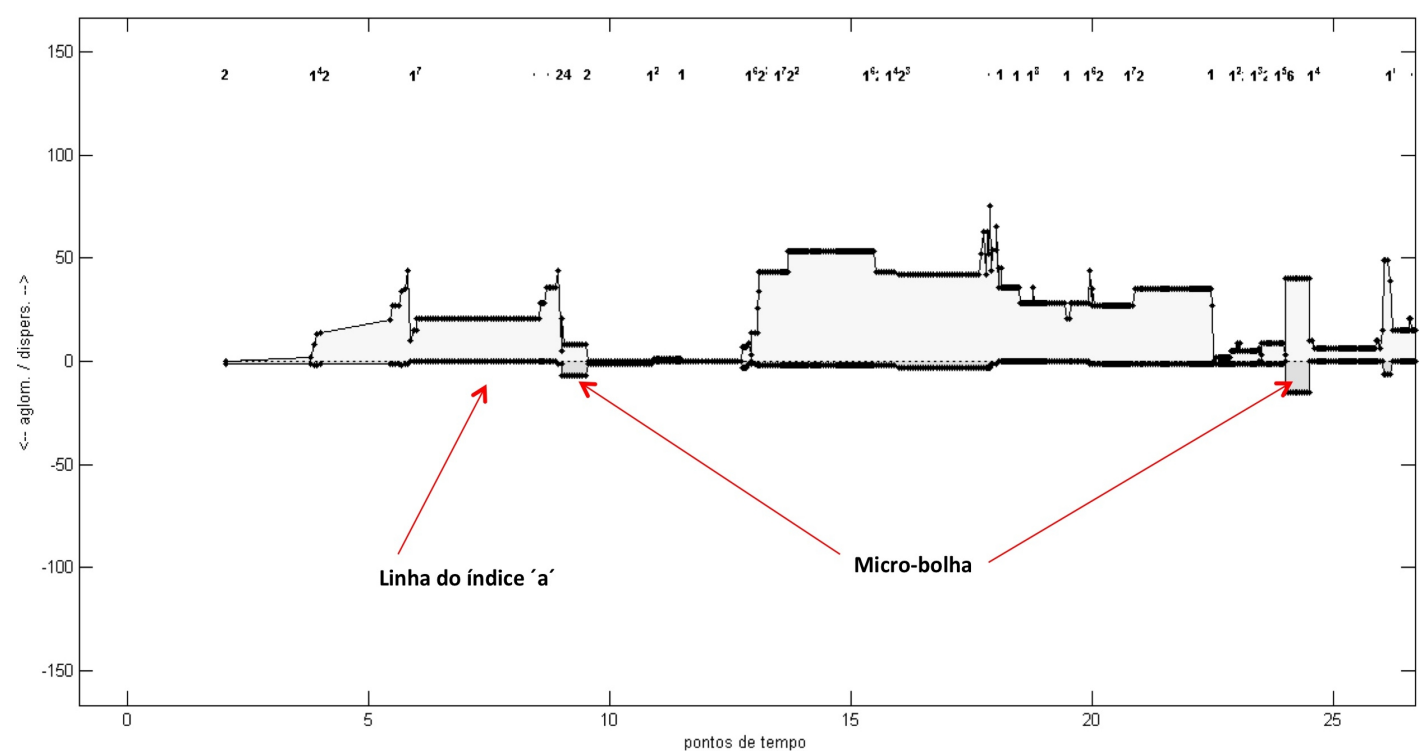

Figura 2: Indexograma de particionamento rítmico (pontos de tempo 0 - 25/ c. 1-6) de

Dérives 1 de Pierre Boulez. Gráfico gerado pelo programa Parsemat (GENTIL-NUNES, 2004).

Essa primeira observação geral sugere forte (quase total) predominância de partes sonoras independentes entre si, sendo a textura fortemente marcada pela atuação de linhas ou vozes independentes em detrimento de blocos ou massas sonoras, ainda que o resultado sonoro geral possa sugerir o contrário. 0 exame do indexograma comparado com a estrutura formal da peça mostra que a textura funciona como elemento central no delineamento da forma.

0 índice $d$ tende para o zero no final da seção (Figura 3), num gradual processo recessivo, enquanto o pouco ativo índice $a$ se afasta do zero, polarizando a organização das partes sonoras, até então quase que exclusivamente dispersiva. A sequência de ações que delineiam a segmentação formal são, neste caso, os movimentos de transferência negativa (-t) e revariância negativa (-r), caracterizando, como mencionado, um movimento de recessão textural ${ }^{11}$, representado no indexograma do c. 26-27 da Figura 8. A textura evolui de um estado

\footnotetext{
${ }^{11} 0$ termo "recessão textural" (textural recession) é empregado por BERRY (1987), para designar o processo de aglomeração das partes sonoras, predominando a interdependência dos componentes sonoros. Ver SANTOS (2014, p. 27) e BERRY (1987, p. 185).
} 
de predomínio da independência das partes sonoras para outro de maior interdependência, concluindo a seção com ambos os índices atingindo o zero.

114

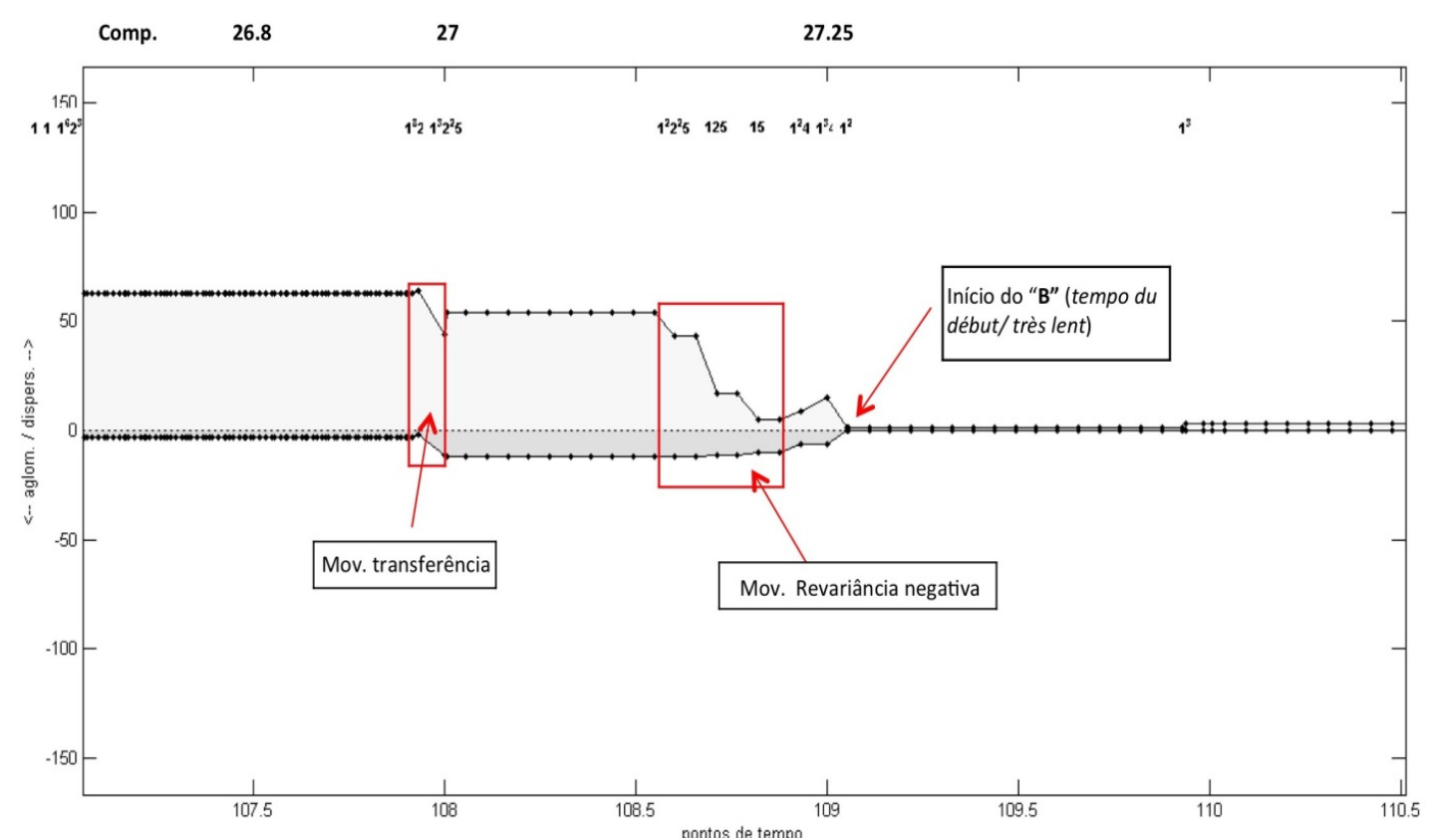

Figura 3: Indexograma de particionamento rítmico (pontos de tempo 107 a 110/ final da seção A) de Dérives 1 de Pierre Boulez. Gráfico gerado pelo programa Parsemat (GENTILNUNES, 2004).

Embora a mudança na dinâmica textural com o objetivo de enfatizar o término de uma determinada seção não seja um procedimento novo - mesmo na música mais tradicional - aqui esse recurso exerce um papel-chave, sobretudo num contexto de ausência de um processo cadencial tonal, como pode ser observado no Exemplo 6, que destaca o trecho equivalente ao indexograma da Figura 3: 


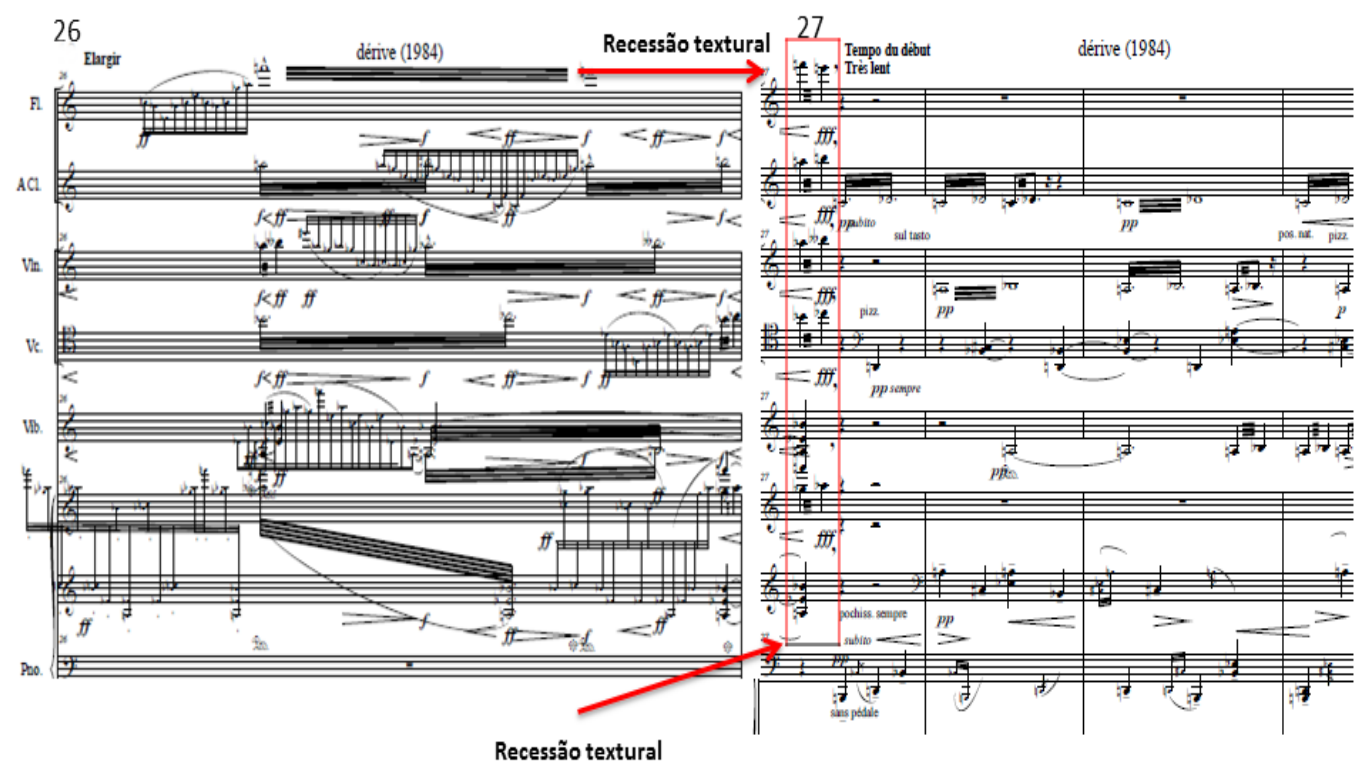

Exemplo 6: Recessão textural “cadencial” no c. 26-27 de Dérives 1 de Pierre Boulez.

Moguillansky (2003, p. 48) afirma que a repentina "modulação" entre os blocos sonoros A e B no c. 23 (Figura 10) sublinha a "explosão" da atividade textural que ali ocorre, confirmando o trecho como clímax estrutural da primeira seção, gerando uma progressão em direção aos compassos 26 e 27 e, logo em seguida, uma recessão textural, que finaliza a seção como apresentado no Exemplo 6. 


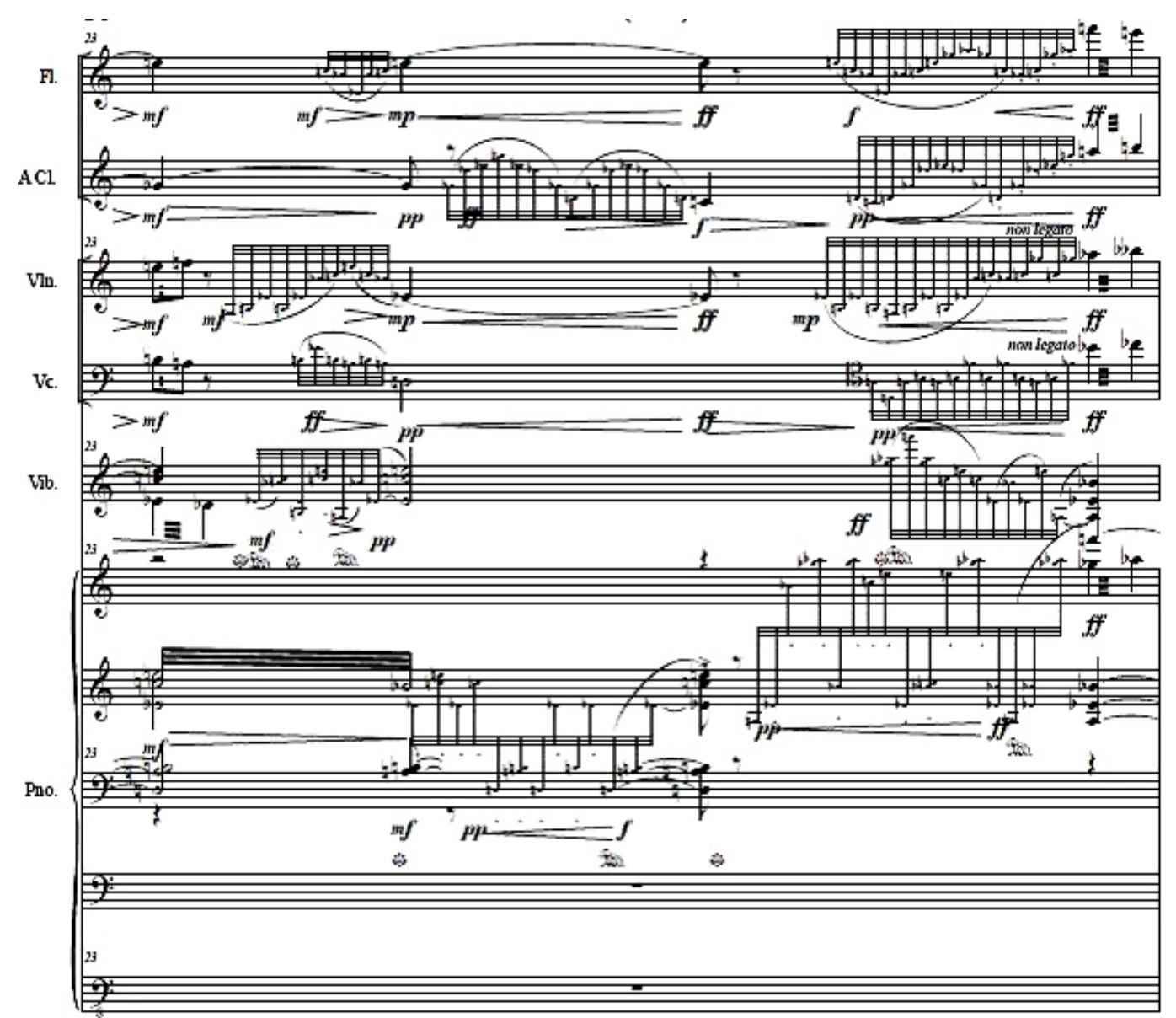

Exemplo 7: "modulação" do bloco A para o B, c. 23 de Dérives 1 de Pierre Boulez.

A seção B é marcada por uma textura bastante contrastante em relação à anterior. A predominância do índice $d$ sobre o índice $a$ se mantém com a presença quase que exclusiva do movimento de revariância, como se pode observar na Figura 11 (a linha em vermelho evidencia o contraste de amplitude da dispersão da seção $\mathrm{B}$ em relação às dispersões das seções A e Coda): 


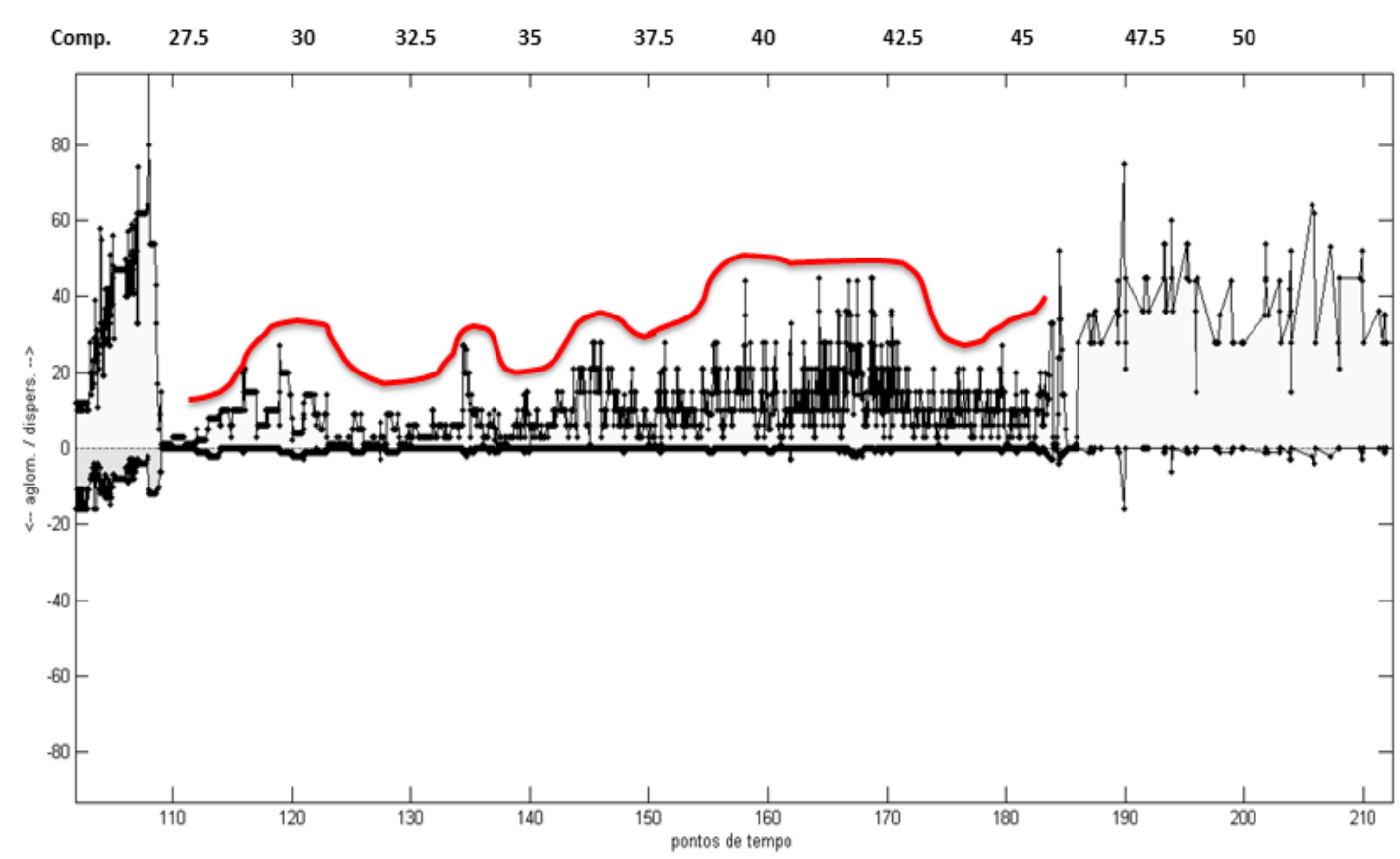

Figura 4: Indexograma de particionamento rítmico - contorno da seção B (pontos de tempo 110 a 220) de Dérives 1 de Pierre Boulez. Gráfico gerado pelo programa Parsemat (GENTIL-NUNES, 2004).

O ritmo harmônico da seção B é mais lento, com um crescendo gradual que tem seu clímax nos c. 40-42. 0 indexograma desse trecho (Figura 5) sinaliza uma coincidência entre o clímax harmônico e o aumento da amplitude do índice de dispersão, ou seja, um aumento tanto na densidade-número da textura quanto na independência entre as partes que a compõem. Esse arco, porém, é relativamente discreto, se comparado com o correspondente da seção anterior, enfatizando o ritmo harmônico lento e o caráter estático do trecho: 


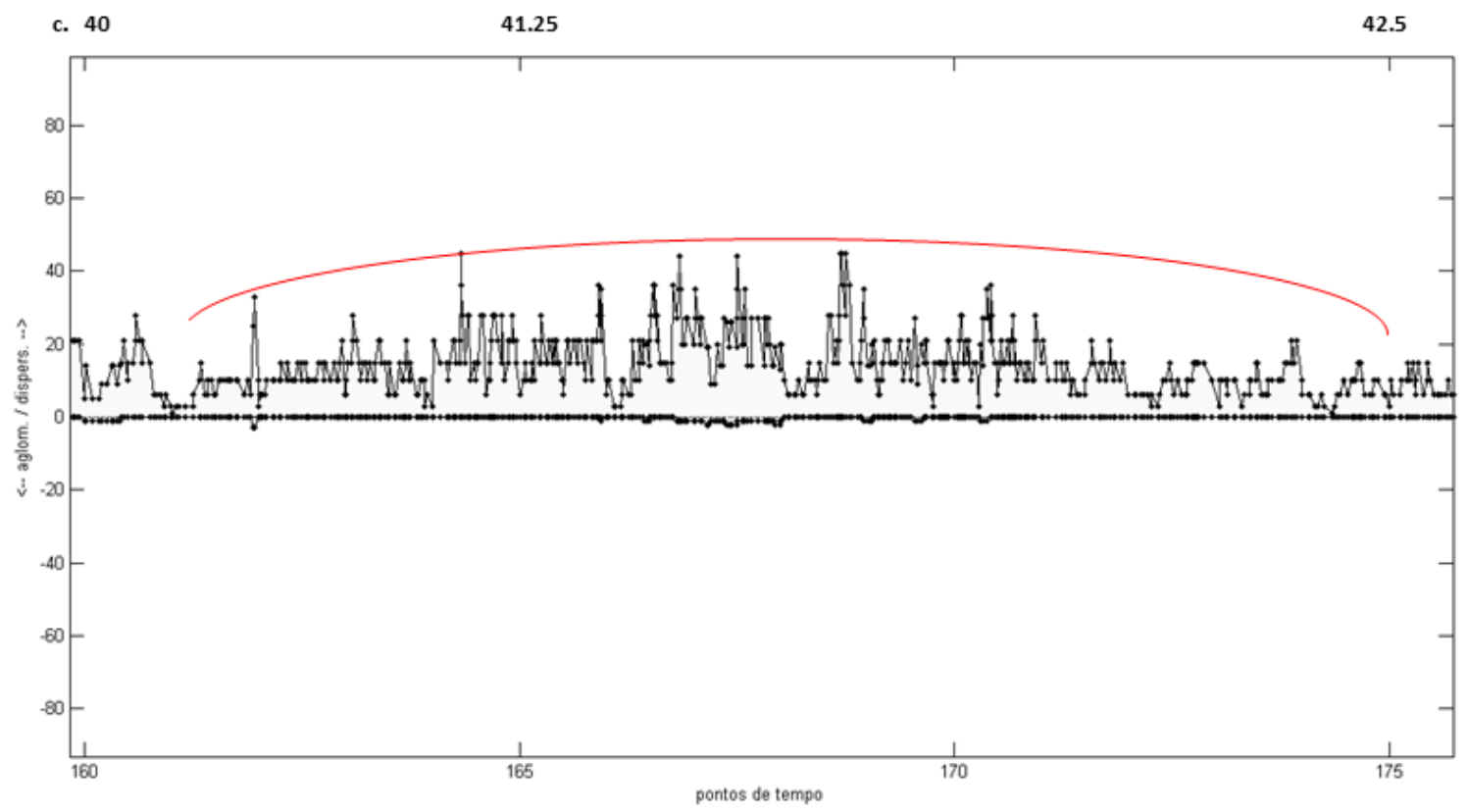

Figura 5: Indexograma de particionamento rítmico (pontos de tempo 160 a 175/Coda) de Dérives 1 de Pierre Boulez. Gráfico gerado pelo programa Parsemat (GENTIL-NUNES, 2004).

A Coda retoma características da seção A, como o andamento inicial e a mesma harmonia (no caso, o acorde A, o único a ser empregado em toda esta seção). Apesar de apresentar um contraste bem menos acentuado em relação à mudança entre as seções A e B, a transição para a Coda também é delineada pela textura. No final da transição (c. 46-47), a densidade-número é novamente reduzida, logo após um ápice do índice $d$, como que preparando um movimento "cadencial" (Figura 6): 


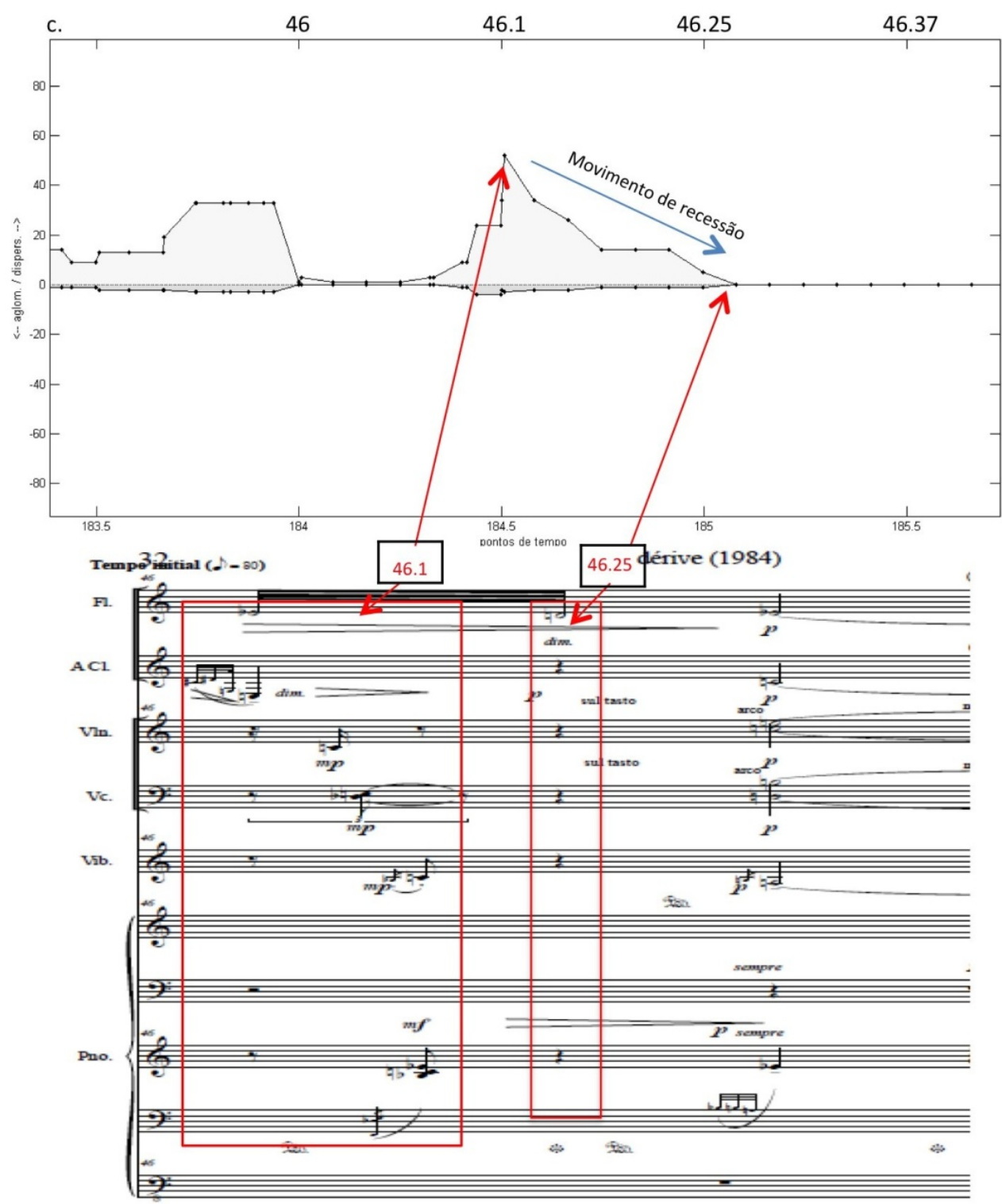

Figura 6: Indexograma de particionamento rítmico (pontos de tempo 184-186) e excerto da partitura (c. 46) de Dérives 1 de Pierre Boulez.

A comparação entre o indexograma e a partitura (Figura 6) revela a condução da textura a um pico do índice $d$ (c. 46-1/2, trecho destacado), seguidos de uma abrupta queda, tanto na densidade-número quanto no próprio índice $d$, que vai a zero. No terceiro tempo do c. 46 já se inicia a configuração textural que marca o começo da Coda.

A Coda é também caracterizada pelo predomínio do índice $d$, tendo, assim como nas outras seções, o movimento de revariância como preponderante. Em contraste com a seção anterior (B), o índice $d$ se mantém estável, apresentando um 
pequeno número de picos e vales, com a densidade-número e a inter-relação entre as partes relativamente estabilizadas, ainda que seu contorno geral evoque semelhanças em relação ao da seção A.

No início da Coda (c. 46, Figura 7), ainda que o andamento retorne gradativamente para o tempo inicial (com a harmonia fechando um ciclo, saindo do acorde $\mathrm{F}$ para o A), é a mudança quase abrupta da textura que permite de fato a constatação de finalização de uma seção (B) e início da outra. Na Coda, tanto a harmonia, construída exclusivamente sobre o acorde A, quanto o andamento, mantêm-se estáveis e regulares, sendo a textura utilizada como "gesto cadencial" conclusivo, a partir do movimento de transferência negativa, ou seja, em direção à aglomeração. Assim, o fim da Coda e da própria peça é mais uma vez marcado por um movimento textural estruturante.

120

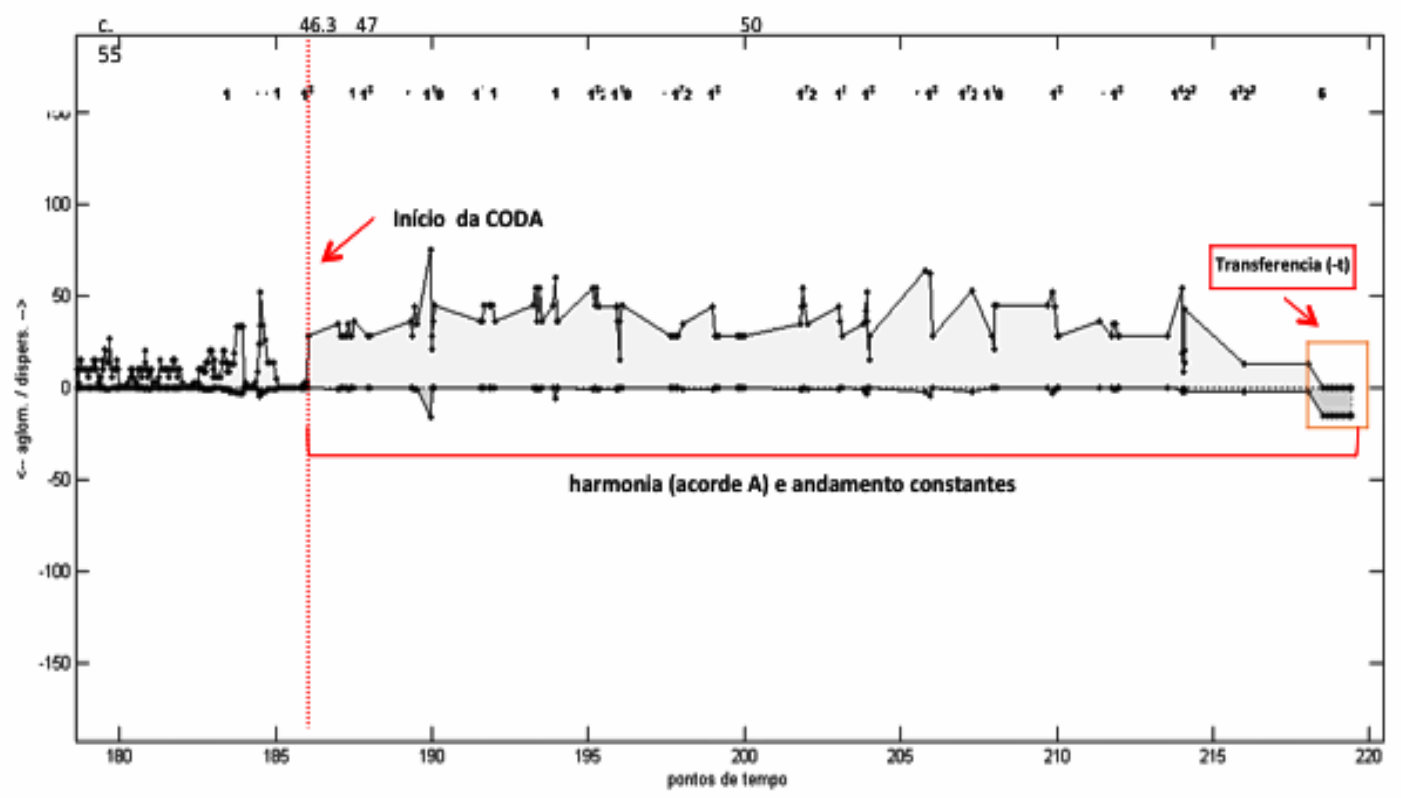

Figura 7: Indexograma de particionamento rítmico da Coda (pontos de tempo 180-220/ fim da seção B e Coda) de Dérives 1 de Pierre Boulez. 


\section{Conclusão}

Em Avant l' artisan furieux (Le Marteau sans Maître), também de Boulez, obra do fim da década de 1950, a observação e análise dos inícios e finais das seções e subseções demonstram como a manipulação da textura nesses trechos funciona como elemento "cadencial", permitindo uma maior clareza do seccionamento. Ainda que a alteração da agógica, por meio de ritardandos, acelerandos e fermatas, auxilie nessa segmentação, é o contraste da configuração textural na transição entre seções/subseções - com alteração ora da densidade-número, ora do predomínio da dispersão ou aglomeração - que caracteriza de fato a segmentação formal.

No nosso entender, é em Dérives 1, obra escrita duas décadas após a Le Marteau, que o papel da textura ganha ainda mais relevância. Ainda que seja uma peça fundada na notação precisa, ela se distingue bastante pela textura menos calcada em linhas ou partes sonoras individuais - ainda que simultâneas - e mais em aglomerados sonoros, cuja análise das partes individuais revela pouco ou nada sobre a obra. Mesmo que a forma aparente seja bastante simples (A-B-Coda) e a agógica também exerça um papel significativo, nessa obra, a textura é sem dúvidas o principal elemento de delineação e contraste seccional.

Em alguma medida, a forma surge de dentro para fora, ou de baixo para cima como diria Adorno ${ }^{12}$. 0 marcado contraste entre as seções A e B revela que sem a centralidade da textura, o próprio sentido da obra ficaria comprometido. 0 predomínio do índice $d$ em praticamente toda obra (Figura 1) expressa o alto grau de independência das partes sonoras entre si, porém, o resultado não é uma clara polifonia num sentido mais comum da palavra, mas antes, aglomerados sonoros, sobretudo em A e Coda, difusos. Por tal razão, esta obra pode ser entendida, em certa medida, como textural, ainda que seja baseada numa notação - em termos de linguagem contemporânea - tradicional e se diferencie da "música textural" característica dos anos 1960 na Europa, centrada numa ampliação da notação musical.

12 "Integral form would emerge from the specific tendencies of all musical details. With the liquidation of musical types, integral form can arise henceforth only from bottom to top, not the other way round" (ADORNO, 2008, p. 213). 


\section{Referências Bibliográficas}

ADORNO, Theodor. Form in the New Music. Music Analysis, Vol. 27, No. 2/3, pp. 201-216, Jul.-Oct. 2008.

BERRY, Wallace. Structural functions in music. Englewood Cliffs: Dover, 1987.

BOULEZ, Pierre. Apontamentos de aprendiz. Tradução Stella Mourinho, Caio Pagano e Lídia Bazarian. São Paulo: Perspectiva, 2008.

Dérives 1. Partitura. Bath: Universal Edition, 1984.

. Pensé la musique aujourd'hui. Paris: Galimmard, 1963.

DELIÈGE, Célestin. Cinquante ans de modernité musicale: De Darmstadt à L'Ircam. Wavre: Éditions Mardaga, 2003.

GENTIL-NUNES, Pauxy. Particionamento rítmico e domínios harmônicos em Le Marteau sans Maître - avant "l'artisanat furieux", de Pierre Boulez. In: Anais do Congresso da Associação Nacional de Pesquisa e Pós-Graduação em Música. Natal: UFRN, 2013.

Análise Particional: uma mediação entre composição musical e teoria das partições. Tese (Doutorado em Música), Universidade Federal do Estado do Rio de Janeiro, 2009.

122

MOGUILLANSKY, Eduardo. Continuidad y autodesarrollo en la música de Pierre Boulez: uma análise de Dérives. Altura-Timbre-Espacio. Cuaderno de Estudio No 5. II MCV, Educa, 2004.

NICOLAS, François. La théorie musicale de Pierre Boulez, 2005. Disponível em: <http://www.entretemps.asso.fr/Nicolas/Textes/Boulez.theorie.htm>Acessado em: 16.05.2013

SANTOS, Jorge Luís de L. A textura musical na obra de Pierre Boulez. Dissertação (Mestrado em Música), Universidade Federal do Rio de Janeiro, Rio de Janeiro, 2014. 